\title{
Formação continuada na prática pedagógica: a Educação Física em questão
}

\author{
Andréa Maria Pires Azevedo * \\ Glycia Melo Oliveira ** \\ Priscilla Pinto Costa Silva*** \\ Thereza Karolina Sarmento Nóbrega ****
}

Marcílio Souza Júnior *****

\begin{abstract}
Resumo: A Formação Continuada é um importante meio para os professores reavaliarem a prática docente, podendo fundar-se como um ambiente que possibilite a construção de diferentes saberes, de repensar e refazer a prática do professor, reorganizando suas competências e produzindo novos conhecimentos. Este ensaio evidenciou a preocupação para com a valorização e incentivo à Formação Continuada de professores de Educação Física, a qual envolve dimensões de natureza humana, histórica, cultural, econômica, políticosocial e técnica. O presente texto procurou refletir a Formação Continuada em torno de três eixos: saberes docentes, competência profissional e prática pedagógica no contexto escolar.

Palavras-chave: Educação Física. Docentes. Competência
\end{abstract} profissional. Prática profissional.

\footnotetext{
*Mestranda. Programa Associado de Pós-Graduação em Educação Física UPE/UFPB. Laboratório de Estudos sobre Lazer, Esporte, Corpo e Sociedade (LAECOS). Universidade Federal da Paraíba (UFPB). João Pessoa, PB, Brasil. E-mail: alanedea@hotmail.com

**Mestranda.Programa Associado de Pós-Graduação em Educação Física UPE/UFPB. Laboratório de Estudos sobre Lazer, Esporte, Corpo e Sociedade (LAECOS). Universidade Federal da Paraíba (UFPB). João Pessoa, PB, Brasil. E-mail: glyciam@yahoo.com.br

***Mestranda. Programa Associado de Pós-Graduação em Educação Física UPE/UFPB. Grupo de Estudos e Pesquisas Sócio-Culturais. Universidade de Pernambuco (UPE). Recife, PE, Brasil.E-mail: laprisci@gmail.com

****Mestranda. Programa Associado de Pós-Graduação em Educação Física UPE/UFPB. Laboratório de Estudos do Treinamento Físico Aplicado ao Desempenho e a Saúde. Universidade Federal da Paraíba (UFPB). João Pessoa, PB, Brasil. E-mail: thereza_karolina@hotmail.com *****Professor do Departamento de Educação da Universidade Federal Rural de Pernambuco. Recife, PE, Brasil. E-mail: marciliosouzajunior@pq.cnpq.br
} 


\section{INTRODUÇÃO}

A Educação é um grande desafio para o Brasil, vivendo problemas históricos que buscam continuamente serem contornados, como por exemplo, o processo de Formação Continuada dos professores de Educação Física. A procura de uma universalização do ensino defende a promoção do conhecimento para todos, em que o processo de Formação Continuada do professor pode ser um artifício para transformações no contexto educacional (SILVA, 1998; GARCIA, 1999; MELLO, 2000).

Nota-se que as Políticas Educacionais têm dedicado atenção ao processo de formação de professores, procurado ofertar maior e melhor qualificação aos professores de Educação Física para que possam enfrentar as constantes e rápidas mudanças que ocorrem na sociedade hodierna (MOREIRA, 2006) e na área de conhecimento específica.

Por entender que a Formação Continuada do professor de Educação Física é uma questão de extrema complexidade, que envolve dimensões de natureza humana, histórica, cultural, econômica, político-social e técnica, surgiu o interesse para a realização do presente ensaio.

Este procura refletir aspectos sobre Formação Continuada em torno de três eixos: nos saberes docentes, na competência profissional e na prática pedagógica do contexto escolar.

\section{FORMAÇÃO CONTINUADA}

A discussão e a participação em cursos de Formação Continuada por parte de professores de Educação Básica têm crescido consideravelmente desde o final do século $\mathrm{XX}$, fato que pode ser compreendido pela decorrência das exigências, em nível mundial, para melhoria da escola básica (INSTITUTO..., 2001). Desde esse período têm sido viabilizadas políticas de formação profissional para professores desse nível de ensino. No entanto, novas reflexões em

Movimento, Porto Alegre, v. 16, n. 04, p. 245-262, outubro/dezembro de 2010. 
torno das exigências da Formação Continuada se propagaram, posto que as políticas de formação profissional não estavam acarretando melhoras no desempenho dos alunos.

A partir dos anos de 1990, o sistema educacional brasileiro apresentou mudanças significativas, como relata os estudos de Macedo (2006), os quais evidenciaram que as políticas de formação pautaram-se nas competências, visando atender a novas exigências e promover qualidade no sistema educacional.

No entanto, os problemas históricos enfrentados pela Educação brasileira, tais como, um ensino elitista e excludente, apontados por Leite e Aranha (2005), dificultam diretamente em atingir as necessidades educacionais básicas dos alunos, comprometendo o conhecimento e as competências para a diversificação do ensino.

Neste cenário, o professor é reconhecido como um simples executor dos saberes, em que especialistas estabelecem o que precisa ser ministrado nas aulas, e o cotidiano dos docentes não são considerados, levando a uma homogeneização destes professores. Assim, observa-se que o professor tende a apenas repassar o conhecimento produzido por um grupo de especialistas (FERREIRA, 2008).

Entretanto, a Formação Continuada do professor, na perspectiva histórico-social tem como princípio a prática pedagógica e situa, como finalidade dessa prática, incentivar os sujeitos a compreenderem os conhecimentos acumulados historicamente pela humanidade. Para que os sujeitos se apropriem do saber escolar de modo a se tornarem autônomos e críticos, o professor precisa estar, ele próprio, apropriando-se desse saber e tornando-se cada vez mais autônomo e crítico (MAZZEU, 1998).

Os conteúdos relacionados à Formação Continuada giram em torno de dois eixos principais: a construção da competência profissional, aliada ao compromisso social do professor, visto como intelectual crítico e como agente da transformação social e; o caráter contínuo e interdisciplinar do processo de formação docente (ANDRÉ et al., 1999).

Movimento, Porto Alegre, v. 16, n. 04, p. 245-262, outubro/dezembro de 2010. 
Sendo assim, junto com Freire (1996), acreditamos que formar é muito mais do que treinar no desempenho de destrezas. A Formação Continuada pode considerar paradigmas que pressuponham a formação do professor a partir de um suporte metodológico, científico e profissional, estimulando a troca de pontos de vista com os outros atores da comunidade escolar (FREIRE, 1996; ARAÚJO; AMARAL, 2005). Silva (2001) corrobora com os autores à medida que considera que a Formação Continuada não abrange apenas o professor, mas, também, inclui os outros profissionais da Educação, como os diretores, os orientadores educacionais, os supervisores pedagógicos e os administradores escolares.

Nesse sentido, a Formação Continuada deve constituir-se como um espaço que possibilite a troca de diferentes saberes, de repensar e refazer a prática do professor, havendo uma reorganização de suas competências e produção de novos conhecimentos (SILVA, 2001).

Este processo de Formação Continuada é preocupação de estudo de vários autores como Masetto (2001), Rosemberg (2002), Batista (2005), que procuram encontrar métodos que promovam progressos no sistema educacional. Desta maneira, observa-se a necessidade de Formação Continuada, no âmbito teórico, pedagógico e educacional, visto que é preciso ampliar as compreensões docentes refletindo nas formas de ensino para haver transformações.

Outros autores fundamentam a Formação Continuada como forma para proporcionar uma melhoria na Educação, em que permita ao professor aprimorar sua prática docente, objetivando atingir as necessidades educacionais dos alunos na sala de aula, a luz dos processos interacionalistas (ZANOTTO, 2002; COLLARES; MOYSÉS; GERALDI, 1999; ALMEIDA, 1994; FUSARI; RIOS, 1994).

A necessidade de preparação adequada para atender aos alunos, exige do professor uma formação capaz de manter uma interação acadêmica preocupando-se em investir no âmbito de atuação

Movimento, Porto Alegre, v. 16, n. 04, p. 245-262, outubro/dezembro de 2010. 
profissional, sob determinada política educacional. A Formação Continuada no âmbito acadêmico vem suprir as necessidades para dar continuidade ao processo de formação para uma transformação do sistema educacional, atendendo os desafios que o campo acadêmico exige (ANDRÉ et al., 1999).

\section{FORMAÇÃO CONTINUADA: SABERES DOCENTES E COMPETÊNCIA PROFISSIONAL}

O resgate do papel e desenvolvimento profissional do professor pelo entendimento da complexidade da prática pedagógica e dos saberes docentes, destacando a importância de se pensar a formação não apenas na dimensão acadêmica, mas, também, em outros âmbitos, tem sido significativamente estudado nas últimas décadas (NUNES, 2001).

Assim, Garcia (1999, p. 27) argumenta:

O desenvolvimento profissional é um desenvolvimento ao longo da carreira desde a formação inicial, à iniciação, ao desenvolvimento profissional contínuo, através da própria carreira [...]. O desenvolvimento profissional é uma aprendizagem contínua, interativa, acumulativa, que combina uma variedade de formatos de aprendizagem.

Para Tardif (2002), a compreensão dos saberes do professor tem uma dimensão mais ampla do que a construída no curso de Formação Inicial. Esses saberes advêm do âmbito familiar, da escola básica, da cultura pessoal e da Formação Continuada. O autor ressalta que essa ampla gama de saberes, que implicam na formação do professor, exige que se tenha a capacidade de dominá-los, integrálos e mobilizá-los, direcionando-os à sua prática. Esses saberes têm um caráter de pluralidade, heterogeneidade e temporalidade, pois, é construído ao longo de toda vida e carreira, portanto, ocorre, também, de forma particularizada na experiência da prática pedagógica no exercício da docência e não apenas na Formação Inicial de forma institucionalizada durante a experiência discente.

Movimento, Porto Alegre, v. 16, n. 04, p. 245-262, outubro/dezembro de 2010. 
Caldeira (2001) atenta para o fato de que a renovação do saber docente está constantemente penetrando na prática e vice-versa. Este exercício de reavaliação crítica contínua da prática docente e o constante intercâmbio entre teoria e prática permitem o aperfeiçoamento profissional.

A Formação Continuada, entendida não apenas como um processo organizado de atualização em função de uma carreira docente diversificada, mas sim como um processo que abrange a dimensão crítico-reflexiva, que entende o professor enquanto sujeito historicamente situado e que articula os saberes científicos, pedagógicos e de experiências docentes, de modo a promover a autonomia profissional que advêm da permanente apropriação do saber e da interação com os demais sujeitos do processo educativo (FALSARELLA, 2004). Pardal e Martins (2005) ainda lembram que essa articulação não é uma ação simples e linear, perpassando por uma necessidade de conceber a Formação Continuada como "um ato permanente, dinamizador da experiência profissional e da reflexão sobre a mesma".

Assim, do ponto de vista de Carvalho (2003, p. 17),

\begin{abstract}
A expressão formação continuada, sendo bem mais ampla que a palavra curso, traz a nossa reflexão, ainda que inadvertidamente, uma idéia mais complexa da linha de tempo e de sucessão de eventos. Se quisermos com essa expressão reforçar a idéia de continuidade, necessariamente, teremos em nossa pauta, outros elementos que também evocam noções cronológicas, pontos de partida, rupturas, simultaneidades, histórias, programas, cronologias, etc [...] talvez possamos entender essa atual emergência da necessidade de formação continuada como uma boa oportunidade de busca de caminhos mais significativos na relação entre produção acadêmica e ensino básico.
\end{abstract}

Uma das principais colaborações da Formação Continuada é quando os professores unem seus saberes, trabalhando de forma conjunta, por meio da comunicação e colaboração, em que cada um pode aprender com o outro (MOREIRA, 2006).

Movimento, Porto Alegre, v. 16, n. 04, p. 245-262, outubro/dezembro de 2010. 
Esses saberes perpassam pelas competências de uma profissão, não havendo competências sem saberes. A competência trata-se de uma capacidade de mobilizar um conjunto de recursos dotados de conhecimentos a fim de enfrentar com eficiência novas e complexas situações (PERRENOULD, 1999). Acredita-se que a competência percebida requer a organização e coordenação de múltiplos processos mentais; que existem diversas dimensões que podem ser avaliadas; que os resultados alcançados pelo indivíduo são mais dinâmicos do que estáticos e podem ser afetados pelos diversos contextos (NASCIMENTO, 1999).

Há o reconhecimento de que a ação humana procura estabelecer uma conexão adequada entre os componentes intelectuais e emocionais, ambos aprimorados pela Formação Continuada, ou seja, um componente representado pelos conhecimentos e habilidades intelectuais do indivíduo e outro componente capaz de determinar o modo mais apropriado da utilização deste componente intelectual (SOUZA, 2006).

Nesse contexto, pautar a Formação Continuada nos saberes docentes, em especial na sua materialização na prática pedagógica e nas competências específicas da área torna-se relevante no sentido de abrir os horizontes no campo de trabalho, oferecendo mais espaço às práticas, muito embora, essa, ainda não seja a concepção mais comum da Formação Continuada, entendida comumente apenas como capacitação educacional alcançada por meio de cursos, oficinas, seminários, palestras e módulos de ensino com o objetivo maior de progressão na carreira e aprofundamento teórico na área, esquecendo de elementos mais complexos que envolvem o conceito ampliado de Formação Continuada (PARDAL; MARTINS, 2005).

Assim, acredita-se que a melhoria da qualidade do ensino pode ser impulsionada por pesquisas que informem a elaboração de Políticas Educacionais mais abrangentes, cujas medidas possibilitem o encaminhamento de ações capazes de envolver diversos aspectos, dentre eles, os referidos anteriormente: Formação Continuada do educador, seus saberes e competências profissionais.

Movimento, Porto Alegre, v. 16, n. 04, p. 245-262, outubro/dezembro de 2010. 


\section{Formação ContinUADAe o CONTEXTO ESCOLAR EM EduCAÇÃo Físıca}

Evidenciamos que a Formação Inicial não se encerra em si mesma, devendo, portanto, articular-se com diferentes esferas da formação e da práxis dos professores de Educação Física em suas dimensões acadêmicas, sociais e políticas, ou seja, na Formação Continuada (SILVA, 1998; ANDRÉ et al., 1999).

A Formação Continuada no campo da Educação Física, segundo Molina Neto (1997a 1997b), tem se apresentando de maneira comercial e desvinculada da realidade educacional. $\mathrm{O}$ autor se propôs a observar 15 eventos de Formação Continuada em Educação Física e dialogou com os professores participantes destes. Diante destes dados contatou que esse tipo de formação vem se assentando em cursos de pequena duração, de 20 e 40 horas ministrados por um especialista, como se fosse uma supermercado de cursos; em atualizações e atividades de repasse de informações como transferência de conhecimentos preexistentes. O autor aponta, sob um olhar crítico a essa perspectiva convencional constatada, a escola como um importante campo de formação. Nesta, o professor de Educação Física precisa investigar autonomamente sua própria prática.

Essa reflexão sobre a própria prática se apresenta ainda mais urgente, quando constatamos certo descompasso da Formação Inicial com essa necessidade.

[...] por mais que tenham conhecimentos específicos para a prática, fica uma lacuna no que diz respeito ao desenvolvimento de uma capacidade reflexiva dos graduandos sobre sua própria prática. Os processo reflexivos são negados, já que o currículo se constitui numa estrutura terminalista, com os estágios ao fim do curso, impossibilitando uma reflexão posterior em outros espaços do processo de formação (BERNARDI; SANCHOTENE; MOLINA, 2010, p. 1).

Movimento, Porto Alegre, v. 16, n. 04, p. 245-262, outubro/dezembro de 2010. 
Entretanto percebemos que essa superação de perspectiva constitui-se com limitações, consolidadas pela própria história da área de conhecimento. O que se observa é que a Educação Física ainda não ultrapassou a estreiteza de uma formação eminentemente técnica, dedicada ao fazer e que pouco valoriza o refletir sobre o fazer, o que termina por restringir a prática pedagógica à seleção e aplicação de procedimentos instrumentais (ALVES, 2005), não havendo tanto sentido a procura por uma Formação Continuada, já que esta se direciona a reflexão e reconstrução do fazer a partir de diversificados saberes.

Considerando que o sucesso profissional depende tanto da utilização adequada de conhecimentos e procedimentos quanto do sentimento de domínio (segurança) manifestados no desempenho profissional, Nascimento (1999), relata as fases de construção e testagem de um instrumento psicométrico (Escala de Auto-Percepção de Competência Profissional em Educação Física e Desportos). O estudo envolveu um total de 100 professores Mestres e/ou Doutores que atuam no Ensino Superior de Educação Física nas Universidades Portuguesas, encontrando 31 tipos de competências. Para tanto, o nível ou a magnitude da competência profissional percebida foi operacionalizado não como uma medida simples de uma tarefa específica do profissional, mas como uma medida composta que refere-se a soma de respostas de itens sobre diferentes competências no domínio de conhecimentos e habilidades necessárias ao desempenho profissional da área.

Em outro estudo, realizado por Oliveira e Ramos (2008), vimos revelado o quanto é importante o incentivo da escola ao professor para a efetiva continuação e aprimoramento dos saberes referentes à sua prática profissional. Os autores destacaram os saberes da formação e da experiência como fundamentais para a atuação profissional na área escolar. A pesquisa pôde detectar que os saberes oriundos da prática e da experiência foram os maiores contribuintes para a construção do saber da professora participante deste estudo, minimizando o distanciamento da realidade escolar e sua prática pedagógica.

Movimento, Porto Alegre, v. 16, n. 04, p. 245-262, outubro/dezembro de 2010. 
Num plano Governamental encontramos a Rede Nacional de Formação Continuada de Professores composta por Universidades Brasileiras ${ }^{1}$ em parceria com o Ministério de Educação (MEC), que desde 2004, atuam em Redes Estaduais e Municipais de ensino para desenvolver a Formação Continuada de professores de Educação Básica em áreas específicas, como por exemplo, na Educação Física. A ideia tem se dado no apoio à pesquisa, a produção de material didático e na realização de cursos. No caso da Educação Física, que acontece juntamente com a área de Arte, três Universidades tem assumido esse papel: 1 - Universidade Federal do Rio Grande do Norte (UFRN) - Paideia; 2 - Pontifícia Universidade Católica de São Paulo (PUC-SP) - Centro de Artes e Educação Física, 3 - Universidade Federal do Rio Grande do Sul (UFRGS) - Centro de Artes e Educação Física.

Vemos então, várias iniciativas de estudos e implementações na Formação Continuada em Educação Física, entretanto, percebemos que o cenário escolar ainda não consolidou a busca permanente por novos saberes que reinventem constantemente suas práticas pedagógicas.

Desse modo, é importante que o professor de Educação Física suplante a visão reducionista de corpo-objeto, na qual o corpo do aluno é considerado um objeto a ser manipulado e melhorado em seu rendimento; priorizar práticas significativas que tenham a expressão corporal como linguagem e que contribuam para a formação de indivíduos capazes de exercer conscientemente sua cidadania.

\footnotetext{
${ }^{1}$ As áreas de Pesquisa apoiadas pela Rede com as respectivas instituições são as seguintes: 1) Alfabetização e Linguagem (Universidade Federal de Pernambuco-UFPE; Universidade Federal de Sergipe-UFS; Universidade Federal de Minas Gerais- UFMG; Universidade Estadual de Ponta Grossa-UEPG; Universidade de Brasília-UNB; Universidade Estadual de CampinasUNICAMP); Educação Matemática e Científica (Universidade Federal do Pará- UFPA; Universidade Federal do Rio de Janeiro-UFRJ; Universidade Federal do Espírito Santo- UFES; Universidade Estadual Paulista- UNESP; Universidade do Vale do Rio dos Sinos-UNISINOS); Ensino de Ciências Humanas e Sociais (Universidade Federal do Amazonas-UFAM; Universidade Federal do Ceará-UFC; Pontifícia Universidade Católica de Minas Gerais-PUC-SP); Gestão e Avaliação da Educação (Universidade Federal da Bahia-UFBA; Universidade Federal de Juiz de Fora-UFJF; Universidade Federal do Paraná-UFPR). As Universidades referentes à área de Artes e Educação Física estão descritas no texto.
}

Movimento, Porto Alegre, v. 16, n. 04, p. 245-262, outubro/dezembro de 2010. 
A partir do exposto, e tomando como inspiração uma experiência realizada na Rede Estadual de Educação de Pernambuco em parceria com o Grupo de Estudos Etnográficos em Educação Física e Esporte (ETHNÓS) da ESEF-UPE, ensaiamos apontamentos para construção de uma concepção e materizalização de Formação Continuada em Educação Física na perspectiva histórico-social, contribuindo para o enfrentamento dos problemas e desafios da realidade educacional brasileira e para a consolidação de ações para as transformações dessa realidade.

Tal experiência aponta três dimensões imprescindíveis para pensarmos e implantarmos uma Formação Continuada em Educação Física: 1 - os sujeitos; 2 - os processos e 3 - os produtos (LORENZINI et al., 2009).

No que concerne aos sujeitos, a experiência sugere uma articulação e mobilização dos diversos sujeitos civis e políticos, pessoais e institucionais, pois, isoladamente, cada um desses não consegue efetivação de sua intencionalidade. Tais sujeitos precisam se apresentar preocupados, engajados e corresponsáveis com a formação.

Propõe-se, na gestão central, ter-se uma articulação entre representações, como por exemplo, a Secretaria de Estado, a Secretaria Executiva, as gerências de ensino e a instituição parceira, nesse caso, uma Universidade. Na gestão direta da formação sugerese uma equipe específica de Educação Física composta por assessores, técnicos das gerências e professores, entre esses, docentes especialistas em áreas específicas do conhecimento em Educação Física, no que se refere à currículo, metodologia, conteúdos (jogo, esporte, dança, ginástica, luta), avaliação, dentre outros; e ainda professores formadores, capazes de aglutinar e mobilizar demais professores, que, em escolas nucleadoras, descentralizarão o processo de repasse das orientações, produção das ações docentes e coleta dos materiais esperados.

No que diz respeito ao processo, apreendemos da experiência ser importante partir de uma análise da Educação Física na atual

Movimento, Porto Alegre, v. 16, n. 04, p. 245-262, outubro/dezembro de 2010. 
Política Educacional da instância promotora da Formação Continuada, nesse caso, da Secretaria de Educação do Estado. Indica-se, junto com os professores da Rede, num processo de socialização da produção dessa análise, como por exemplo, no site da instância promotora, a problematização do ensino da Educação Física no contexto escolar. Essas duas ações podem se dar em seminários iniciais presenciais com a equipe específica, os professores especialistas e os professores formadores, alimentados pelas contribuições dos professores da Rede coletadas via internet.

A experiência apontou, em seminários de elaborações preliminares a mobilização de uma representatividade ou totalidade dos professores de Educação Física da Rede para se apropriarem da produção inicial, analisarem, criticarem e reelaborarem de forma propositiva; em seminários regionais, a disseminação do fruto do trabalho coletivo e as orientações para outras produções específicas a serem realizadas pelos professores no âmbito de suas escolas; por fim, em encontro estadual, com a totalidade dos professores, num formato de evento acadêmico, a socialização das elaborações dos professores e estabelecimento do diálogo sobre a produção.

No que se refere aos produtos, sugere-se a elaboração de materiais documentais que registrem o potencial produtivo do agir pedagógico dos professores de Educação Física no cotidiano do contexto escolar. O produto da análise política constituiu-se um documento provocador de debates e sugestões, para que no decorrer do processo seja reelaborado e, assim, conseguir concretizar uma concepção curricular para o ensino da Educação Física em que estejam presentes os fundamentos para o ensino desse componente do currículo.

Fez-se necessário também indicar, que a partir do currículo, os professores da Rede se organizem e produzam um programa de ensino específico de sua escola, sistematizando os saberes escolares no tempo de escolarização; estruturem e documentem relatos de sua experiência para que a escola se consolide como espaço de reflexão e produção da cultura local sem perder de vista uma cultura geral.

Movimento, Porto Alegre, v. 16, n. 04, p. 245-262, outubro/dezembro de 2010. 
Indicou-se também o texto didático como mais um importante produto da Formação Continuada, pois, muitas vezes, nossa área é compreendida quase que exclusivamente como a área corporal. Assim, é possível propor a compreensão de que podemos usar de outras linguagens como a imagética, a falada e a escrita e todas devem ser reconhecidas como produtoras de conhecimento. O texto didático pode ser elaborado na intenção de servir de recurso pedagógico de uso do professor e do aluno, e, ainda, como ferramenta de interação de ambos com os conteúdos de ensino.

Por fim destacamos que a Formação Continuada precisa contemplar a reestruturação da prática docente tanto pela contínua reflexão e reconstrução de novos saberes científicos e pedagógicos produzidos na Formação Inicial, quanto pelos saberes adquiridos pela experiência. Isso significa que a formação docente não se restringe a aprendizagem de conceitos e conteúdos, mas da constante reflexão de sua ação pedagógica, a qual será amadurecida a partir da experiência construída diariamente, o que capacita o profissional enxergar mudanças significativas na área e na sua própria intervenção pedagógica.

\section{CONSIDERAÇÕES FINAIS}

Numa perspectiva histórico-social a Formação Continuada pressupõe uma articulação entre saberes docentes, competências profissionais e prática pedagógica. Esses três eixos se constituem como inter-relações da formação e ação docente, permitindo a compreensão e vivência da Formação Continuada como um importante meio para os professores reavaliarem a prática docente, podendo fundar-se como um ambiente que possibilite a construção de diferentes saberes, de repensar e refazer a prática do professor, reorganizando suas competências e produzindo novos conhecimentos.

Este ensaio evidenciou a preocupação para com a valorização e incentivo à Formação Continuada de professores de Educação Física, nesta perspectiva, procurando atender aos anseios específicos da área, engajada no contexto escolar como um todo, tendo a prática

Movimento, Porto Alegre, v. 16, n. 04, p. 245-262, outubro/dezembro de 2010. 
pedagógica como objeto central, oferecendo ao professor o reconhecimento de sua capacidade produtiva, na vivência de sua própria ação docente.

Movimento, Porto Alegre, v. 16, n. 04, p. 245-262, outubro/dezembro de 2010. 
Continuing education in educational practice: Physical Education in question

Abstract: The continuing education is an important way for teachers to re-evaluate teaching practice, and establish itself as an enabling environment for the exchange of different knowledge, to rethink and redo the teacher's practice, reorganizing their skills and producing new knowledge. This research showed a concern for the enhancement and encouragement of continuing education for physical education for education teachers, involved dimensions of human nature, historical, cultural, economic, political, social and technical. This text sought to reflect the ongoing training in three areas: teacher's knowledge, professional competence and pedagogical practice in the school context.

Keywords: Physical Education. Faculty. Professional competence. Professional practice.

\section{Formación continua en la práctica docente: la} Educación Física en cuestión

Resumen: La formación continuada es una forma importante para los profesores volver a evaluar la práctica docente, y establecerse como un ambiente propicio para el intercambio de conocimientos diferentes, repensar y rehacer la práctica del profesor, la reorganización de sus competencias y producción de nuevos conocimientos. Esta prueba demuestra la preocupación por la mejora y el fomento de la Formación Continua de Maestros de Educación Física, que implica las dimensiones de la naturaleza humana, histórica, cultural, económico, político, social y técnico. Este texto refleja la formación continua en tres áreas: conocimiento de los maestros, la competencia profesional y la práctica pedagógica en el contexto escolar.

Palabras clave: Educación Física. Docentes. Competencia profesional. Práctica profesional.

\section{REFERÊNCIAS}

ALMEIDA, Nancy Vinagre Fonseca de. Os modos de pensar do professor: buscando compreendê-los a partir de contextos interativos. 1994. Tese (Doutorado em Educação), Faculdade de Educação, Universidade Estadual de Campinas, Campinas, 1994.

Movimento, Porto Alegre, v. 16, n. 04, p. 245-262, outubro/dezembro de 2010. 
ALVES, Wanderson Ferreira. A formação continuada e o desenvolvimento profissional do professor: paradigmas, saberes e práticas nos cursos de especialização em educação física escolar. Revista Brasileira de Educação Física, São Paulo, v. 19, n. 1, p. 35-48, jan./mar., 2005.

ANDRÉ, Marli et al. Estado da arte da formação de professores no Brasil. Educação \& Sociedade, Campinas, v. 20, n. 68, p. 301-9, 1999.

ARAÚJO, Célia Maria; AMARAL, Vera Lúcia do (Org.). Guia do tutor. Natal: Paidéia/ UFRN; 2005.

BATISTA, Nildo Alves. Desenvolvimento docente na área da saúde: uma análise. Trabalho, Educação e Saúde, Rio de Janeiro, v. 3, n. 2, p. 283-94, set., 2005.

BERNARDI, Guilherme Bardemaker; SANCHOTENE, Mônica Urroz; MOLINA NETO, Vicente. Formação profissional e Educação Física Escolar: contribuições do currículo para a prática docente. Lecturas: Educación Física y Deportes. Revista Digital, Buenos Aires, v. 14, n. 141, feb., 2010. Disponível em: <http://www.efdeportes.com/ efd141/formacao-profissional-e-educacao-fisica-escolar.htm>. Acesso em: 01 maio 2010.

CALDEIRA, Ana Maria Salgueiro. A formação de professores de educação Física: quais saberes e quais habilidades? Revista Brasileira de Ciências do Esporte, Florianópolis, v. 22, n. 3, p. 87-103, 2001.

CARVALHO, Ana Maria Pessoa. A formação do professor e a prática de ensino. São Paulo: Pioneira, 2003.

COLLARES, Cecília Azevedo Lima; MOYSÉS, Maria Aparecida Affonso; GERALDI, João Wanderley. Educação continuada: a política da descontinuidade. Educação \& Sociedade, Campinas, v. 20, n. 68, p. 202-19, dez. 1999.

FALSARELLA, Ana Maria. Formação continuada e prática de sala de aula: os efeitos da formação continuada na atuação do professor. Campinas: São Paulo: Autores Associados, 2004.

FERREIRA, Lílian Aparecida. Ensinando e aprendendo na ação docente em Educação Física. Motriz, Rio Claro, v. 14, n. 1, p. 30-40, jan./mar., 2008.

FREIRE, Paulo. Pedagogia da autonomia: saberes necessários à prática educativa. São Paulo: Paz e Terra, 1996.

FUSARI, José Cerchi; RIOS, Terezinha Azerêdo. A formação continuada dos profissionais de ensino. In: CONGRESSO ESTADUAL PAULISTA SOBRE A FORMAÇÃO DE EDUCADORES, 3, 1994, São Paulo. Anais... São Paulo: UNESP, 1994. p. $19-25$.

GARCIA, Carlos Marcelo. Formação de professores para uma mudança educativa. Porto: Porto, 1999.

Movimento, Porto Alegre, v. 16, n. 04, p. 245-262, outubro/dezembro de 2010. 
INSTITUTO NACIONAL DE ESTUDOS E PESQUISAS EDUCACIONAIS - INEP. Sistema Nacional de Avaliação da Educação Básica (SAEB). Novas Perspectivas. Brasília, 2001.

LEITE, Lúcia Pereira; ARANHA, Maria Salete Fábio. Intervenção reflexiva: instrumento de formação continuada do educador especial. Psicologia: Teoria e Pesquisa, Brasília, v. 21, n. 2, p. 207-215, mai./ago., 2005.

LORENZINI, Ana Rita et al. Programa de formação continuada em Educação Física: sujeitos, processos e produtos. In: TERRA, Dinah Vasconcelos; SOUZA JÚNIOR, Marcílio. Formação em Educação Física e Ciências do Esporte. São Paulo:Goiânia: Hucitec:CBCE, 2009. p. 147-179.

MACEDO, Jussara Marques. Política de Formação/Qualificação de Professores em Exercício no Estado da Bahia. In: SEMINÁRIO DA REDESTRADO - Regulação Educacional e Trabalho Docente, 6. 2006. Anais... Rio de Janeiro, 2006.

MASETTO, Marcos. Docência na universidade. Campinas: Papirus; 2001.

MAZZEU, Francisco José Carvalho. Uma proposta metodológica para a formação continuada de professores na perspectiva histórico-social. Caderno CEDES, Campinas, v. 19, n. 44, p. 59-72, abr. 1998.

MELLO, Guiomar Namo. Formação inicial de professores para a educação básica: uma (re) visão radical. Revista São Paulo em perspectiva, São Paulo, v. 14, n. 1, p. 98-110, jan./mar., 2000.

MOLINA NETO, Vicente. A formação profissional em educação física e esportes. In: CONGRESSO BRASILEIRO DE CIÊNCIAS DO ESPORTE, 10, 1997. Anais... Goiânia, 1997a. , p.36-44.

MOLINA NETO, Vicente. A formação profissional em Educação Física e Esportes. Revista Brasileira de Ciências do Esporte, Florianópolis, v. 19, n. 1, p. 34-41, 1997b.

MOREIRA, Maria José Coutinho. Projeto professor nota 10 - um impacto na prática de formação continuada de professores no Distrito Federal. 2006. Dissertação (Mestrado em Educação), Curso de Educação, Universidade Católica de Brasília, Brasília, 2006.

NASCIMENTO, Juarez Vieira. Escala de auto-percepção de competência profissional em educação física e desportos. Revista Paulista de Educação Física, São Paulo, v. 13, n. 1, p. 5-21, jan./jun., 1999.

NUNES, Célia Maria Fernandes. Saberes docentes e formação de professores: um breve panorama da pesquisa brasileira. Educação \& Sociedade, Campinas, n. 74, p. 27-42, abr., 2001.

OLIVEIRA, Ana Carolina Santana; RAMOS, Glauco Nunes Souto. Construindo saberes pela formação e prática profissionais de uma professora de Educação Física do ensino médio. Motriz, Rio Claro, v. 14, n. 3, p. 252-259, jul./set., 2008.

Movimento, Porto Alegre, v. 16, n. 04, p. 245-262, outubro/dezembro de 2010. 
PARDAL, Luís António; MARTINS, António Maria. Formação contínua de professores: concepções, processos e dinâmica profissional. Psicologia da Educação, São Paulo, n. 20, p. 103-117, $1^{\circ}$ sem., 2005.

PERRENOULD, Philippe. Construir competências é viras as costas aos saberes? Pátio. Revista pedagógica, Porto Alegre, n. 11, p. 15-19, nov., 1999.

ROSEMBERG, Dulcinéa Sarmento. 0 processo de formação continuada de professores: do instituído ao instituínte. Niterói: Walk, 2002.

SILVA, Eurides Brito da. A educação básica pós-LDB. São Paulo: Pioneira, 1998

SILVA, Maria Aparecida de Oliveira. O discurso dos professores sobre a formação continuada. In: REUNIÃO ANUAL DAASSOCIAÇÃO NACIONAL DE PÓS-GRADUAÇÃO E PESQUISA EM EDUCAÇÃO, 24. Anais..., Caxambú, 2001. Disponível em: <www.anped..org.br/reunioes/24/textos>. Acesso em: 30 set. 2009.

SOUZA, Denise Trento Rebello. Formação continuada de professores e fracasso escolar: problematizando o argumento da incompetência. Educação e Pesquisa, São Paulo, v. 32, n. 3, p. 477-492, set./dez., 2006.

TARDIF, Maurice. Saberes docentes e formação profissional. Petrópolis: Vozes, 2002

ZANOTTO, Maria Angélica do Carmo. A formação contínua como possibilidade do aprimoramento da ação de problematizar: análise de uma proposta voltada para professores atuantes em educação especial. 2002. Tese (Doutorado em Educação do Individuo Especial), Faculdade de Educação, Universidade Federal de São Carlos, São Carlos, 2002.

Recebido em: 12.01. 2010.

Aprovado em: 04.05 .2010

Movimento, Porto Alegre, v. 16, n. 04, p. 245-262, outubro/dezembro de 2010. 